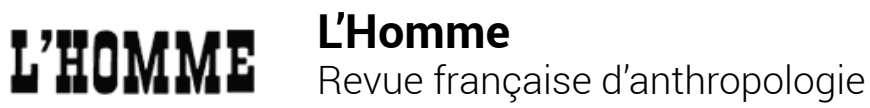

225 | 2018

Varia

\section{Pierre Serna, Comme des bêtes. Histoire politique de l'animal en Révolution (1750-1840)}

\section{Florence Burgat}

\section{(2) OpenEdition \\ 9 Journals}

\section{Édition électronique}

URL : http://journals.openedition.org/lhomme/30829

DOI : $10.4000 / /$ homme.30829

ISSN : 1953-8103

Éditeur

Éditions de l'EHESS

\section{Édition imprimée}

Date de publication : 15 mars 2018

Pagination : 203-204

ISBN : 978-2-7132-2733-2

ISSN : 0439-4216

\section{Référence électronique}

Florence Burgat, «Pierre Serna, Comme des bêtes. Histoire politique de l'animal en Révolution (1750-1840) », L'Homme [En ligne], 225 | 2018, mis en ligne le 15 mars 2018, consulté le 06 janvier 2021. URL : http://journals.openedition.org//homme/30829; DOI : https://doi.org/10.4000/lhomme. 30829

Ce document a été généré automatiquement le 6 janvier 2021.

(c) École des hautes études en sciences sociales 


\title{
Pierre Serna, Comme des bêtes. Histoire politique de l'animal en Révolution (1750-1840)
}

\author{
Florence Burgat
}

\section{RÉFÉRENCE}

Pierre Serna, Comme des bêtes. Histoire politique de l'animal en Révolution (1750-1840). Paris, Fayard, 2017, 444 p., notes bibliogr., ill., index (« L'Épreuve de l'histoire »).

1 Les animaux, nous apprend-on dans les cours de philosophie de classes terminales, n'ont pas d'histoire. C'est évidemment faux, et en plusieurs sens. Historien de la Révolution française, Pierre Serna se propose «de construire une histoire qui se voudrait totale ", celle des années 1750-1840 que marque un «face-à-face unique entre l'homme et l'animal» (p. 12), et de nous livrer «l'histoire politique des rapports entre les hommes et les animaux » (p. 13). Car le statut des uns et des autres, pris dans une relation de miroir, évolue sous l'effet de discours croisés : «En élargissant le cercle de la citoyenneté jusqu'à ceux que l'on considérait comme des sujets à peine entrés dans l'humanité, en faisant des droits naturels les fondements du droit positif, en utilisant des centaines de fois dans les discours le mot "esclavage" comme métaphore de l'homme réduit à la condition d'un animal domestique sous la férule des despotes, les inventeurs du monde politique ont pensé aux êtres humains d'abord, mais aussi aux animaux » (p. 217).

2 La démarche de Pierre Serna est novatrice, car «la place de l'animal - dans sa spécificité d'être animal - en Révolution a jusqu'ici peu intéressé les historiens du politique » (p. 18). Cette étude tient ses promesses d'une histoire totale : elle fait place aux animaux eux-mêmes par leur présence et les usages qu'ils subissent, à l'animalité, notion désignant la part trouble de l'humain (Sade), à l'animalisation, un procédé de 
dévalorisation de certains humains qui se nourrit du statut réifié des animaux, inscrit dans le Code civil de $1804^{1}$.

3 Les animaux sont omniprésents en ville, notamment à Paris. Chevaux, chiens (l'accident dont fut victime Rousseau, renversé par un chien dans la descente de Ménilmontant, est rappelé [p. 37]), cochons, troupeaux de bêtes à cornes, constituent «autant de périls potentiels» (p. 29). On croise aussi des perroquets, des singes, des bêtes fauves, d'autres savantes, qui font l'objet d'exhibitions dans de petits théâtres de rue ou dans des foires. À cela s'ajoutent les combats d'animaux (taureaux, chiens, ours, loups), pratique ancienne qui attire une foule (pp. 59-71) dont les penchants sanguinaires font s'interroger certains auteurs de l'époque (p. 69). La culture de l'insensibilité, en particulier dès l'enfance, est incompatible avec la pacification des mœurs, et cette pensée, que l'on trouve chez Kant, fait son chemin dans l'esprit du législateur depuis le XVIII ${ }^{\mathrm{e}}$ siècle ${ }^{2}$. Les animaux destinés à la boucherie sont abattus à la vue de tous: «La rue offre une mise en scène où le boucher ès qualité inflige un spectacle de cruauté ", dont l'auteur Louis-Sébastien Mercier rend compte en de terribles pages dans son Tableau de Paris ${ }^{3}$ (pp. 44-45). Contrairement à une idée qui circule aujourd'hui, les animaux de boucherie étaient très maltraités à toutes les étapes d'un processus les menant à la tuerie : "poulains écrasés sous la charge, veaux sevrés trop tôt [...] logement des animaux, origine de bien des maladies » (p. 167). Ce n'est pas tout. La passion cynégétique est une réalité révolutionnaire : «S'il y a des êtres vivants qui ne furent pas à la fête durant ce premier été de la Révolution, ce furent bien les animaux des bois qui subirent un massacre sans précédent ", le droit de chasse ayant été délivré à tous (p. 223). Le respect des animaux, étape obligée de la pacification des mœurs interhumaines, se heurte donc à bien des pratiques, dont également celle de la vivisection, dénoncée par Jacques Peuchet dans son Dictionnaire de police et municipalités ${ }^{4}$. Enfin, le végétarisme, sous la plume de Georges Toscan, premier bibliothécaire du Muséum, s'impose comme la «dernière révolution à accomplir » (p. $147)^{5}$. Un ensemble de préoccupations se dessine, que la police énumère : éduquer le peuple, veiller à sa sécurité et à sa santé, mais aussi prévenir sa violence, et donc protéger les animaux d'une brutalité qui s'exerce largement. Voilà bien un programme politique.

Un autre projet porte une mission politique : la ménagerie du Jardin des plantes est un lieu d'expérimentation de la réorganisation sociale du monde (p. 82), qui comprend trois acteurs: "Derrière la cage se tient le monde des scientifiques qui pense et ordonne l'exhibition des animaux [...] ; dans la cage se trouve une collection d'animaux vivants acquis et conservés [...]; devant la cage se place la masse d'un public à éduquer » (p. 83). Cuvier, Bernardin de Saint-Pierre, Lamarck, Geoffroy Saint-Hilaire, Thibaudeau, Lacépède - le Muséum « réunit les personnes les plus savantes de France, puis d'Europe (p. 127) - sont impliqués dans l'entreprise. Non seulement « il manque de tout à la ménagerie » (p. 95), mais, en outre, la captivité affecte les animaux, qui prennent leur progéniture en aversion, par exemple, et montrent des signes de mélancolie (pp. 108-110); beaucoup meurent. La ménagerie est aussi «l'indice microhistorique de la vaste mise en coupe du monde africain, américain, asiatique et astral » par les Européens (pp. 145-146). La mode est à l'« amélioration» des animaux de rente (c'est-à-dire à la sélection de races à des fins de production), en particulier les « bêtes à laine ». La figure de François-Hilaire Gilbert, « vétérinaire-voyageur ", devenu célèbre, livre de nombreux et précieux témoignages. Rédacteur de la biographie d'un 
bélier, auquel il promet d'échapper au boucher, Gilbert est, en revanche, violemment opposé à l'existence des loups, « un monde à détruire » (p. 186).

5 C'est une page inédite, contrastée et passionnante, de la Révolution française, que nous offre Pierre Serna.

\section{NOTES}

1. Voir la partie $5:$ "L'invention de l'homme-singe : 1802 et la catastrophe racialiste » (pp. 319-364).

2. Cf. Pierre Serna, L'Animal en République. 1789-1802, genèse du droit des bêtes, Toulouse, Anacharsis, 2016 («Essais. Série histoire »).

3. Les deux premiers volumes de cet ouvrage sont parus en 1781 à Neuchâtel, puis une première édition complète en 12 volumes à Amsterdam entre 1782 et 1788.

4. En deux volumes (Paris, Panckoucke / Liège, Plomteux, 1789-1791).

5. Voir aussi le chapitre XIV : «1789-1803 : république écologique et démocratie végétarienne » (pp. 288-315). 